\title{
The value of students' feedback
}

\author{
Alina Georgeta Mag* \\ University "Lucian Blaga" of Sibiu, Faculty of Social and Human Sciences, Department for Teacher \\ Training, Calea Dumbrăvii Nr.34, 550324, Sibiu, România
}

\begin{abstract}
Quality teaching is directly related with effective and high-quality feedback, and such arguments are well supported by the findings of recent studies. Feedback constitutes a central aspect of learning, yet has been largely neglected in research to date, particularly from the student's point of view. This gap in practice has been picked up by the Department for Teacher Training of "Lucian Blaga" University of Sibiu. This paper explores students' perception of feedback. First year students enrolled at the Primary and Preschool Pedagogy program were invited to attend focus groups and individual interviews. A questionnaire was developed from themes identified in the focus groups and was administrated to a large group of undergraduate students in the second part of the study. This paper reports on the focus groups and the themes that emerged from the data. Findings revealed that receiving late and minimal feedback during the semester was a common cause of students' dissatisfaction. Responses were mixed to the question of whether enough feedback was being provided. They indicated they wanted a more proactive approach from the academic staff, because they recognized the value of feedback as central to improved learning.
\end{abstract}

\section{Introduction}

The Romanian educational system is facing these days huge changes and difficulties: students with different needs, mass media's influence, the local community's impact and a more aggressive climate that affects the relationships between teachers and students. Indeed, as it is seen increasingly better recently, school reality requires a much greater development of the specifics of communication, reaching many psychological aspects. It is important to rebalance all the rules that the teacher needs to know, to practice and to innovate every day in direct relationships with students. Feedback serves a variety of purposes including the grading of achievements, the development of students' understanding, skills and motivation.

It has long been recognized, by researchers and practitioners alike, that feedback plays a decisive role in learning and development, within and beyond formal educational settings. Everyone learns faster and much more effectively, when he gets a clear sense of how well he is learning and what he might need to do in order to improve. Also, students' feedback about how they feel each academic experience and the relationship with each teacher needs to be provided and valued, as a constant approach in a modern educational system. Despite its obvious importance, feedback continues to be a common source of students' dissatisfaction,

\footnotetext{
* Corresponding author: alina.mag@ulbsibiu.com
} 
according to different studies [1-2]. An increasing reliance on considerable debate continues over the extent to which students value feedback.

\section{Problem statement}

If feedback is to be framed as purposeful dialogue, then both students and teachers have significant roles to play. Students must be willing and able to provide feedback to teachers not only about their learning needs, but also about the teaching they experience. In turn, teachers must create the conditions that support active students learning. The vision to develop young people who will be confident, connected, actively involved and life-long learners, requires both teachers and students to reconceptualize their roles in teaching, learning and assessment and for both parties to rethink the nature of the teacher-student relationship [2].

No longer can teachers expect to control the teaching and learning of their students. Nor can they expect students to be passive recipients in learning and assessment. Rather, teachers are now expected to foster learning focused partnerships with their students, at the same time developing the reflective habits of mind, that will enable them to become independent, autonomous learners. By necessity, for students to participate fully in a productive and learning focused partnership with teachers, they must be both willing and able to take ownership of and responsibility for their learning. Students must also possess the confidence to articulate their learning to others and be assured that such disclosure is essential to the improvement of learning and teaching. It is obvious that creating a trustful, mutually supportive and respectful learning environment is therefore critical to students' participation and development [3].

This paper will be of interest to teachers that are trainers for future teachers and their students, at all levels, because it provides insides into students' perspectives about the role feedback plays in the enhancement of their learning, the kind of experiences and interactions needed to support their learning needs and the dispositional qualities teachers need to create a trustful and respectful environment.

\section{Theoretical foundation and related literature}

Effective and high-quality feedback has been identified as a key element of quality teaching and learning, and such arguments are well supported by the findings of many studies [4-6]. If it is used appropriately, feedback is an essential component of assessment for both teaching and learning and it can lead to substantial visible learning gains [7]. If, as required in a modern university, teachers and learners work in partnerships to aid improvement, feedback can be conceptualized as the crucial link between teaching and learning [1]. Within the context of the classroom, feedback can be given in a planned or spontaneous manner and in a multitude of forms: written comments, grades, marks, oral responses and non-verbal gestures. Recognizing the pivotal role that learners play in learning and assessment, the most valuable form of feedback is now commonly considered to be that which is constructed jointly by teachers and students as a dialogue based on their own reflections about each course [8].

Given the importance of feedback to learning, several studies have focused on teachers' conceptions and use of feedback to enhance student's learning [2,4,9]. Pânişoară (2017) for example, found that teachers had different perceptions of their role and that of students in the feedback process. Traditional education envisaged the feedback process to be controlled by teachers with students assigned the role of passive recipients and consumers of teachers' feedback. In the past, even research treated students as objects: research was done on them, 
with the agenda and framework set purely by adults. Students have been silenced, limited and even excluded. Injustice, dissatisfaction, new ideas and raw needs are feeling change [2].

Currently the attitudes, opinions and lived experience of students are being given air, in a student-centered modern education. Innovations are being made in the way research is conceived and carried out. It's role in students' lives is changing. Students act as researchers, and researchers work with students in new ways driven by a rights perspective. Teachers should consider students' voice in order to reflect on their own ideas, experiences and ways of practicing, considering students as educational partners. Jones (2009) argues that these are the contemporary understandings related to the roles and responsibilities assigned to teachers and students. Teachers should place a greater emphasis on students' role, viewing them as active participants, capable of generating feedback information about their own learning [9].

However, as noted in other studies [1,7] while it is important to gain insights into teachers' feedback-related understandings and practice, such insights provide an incomplete picture of the ways in which is used to support and enhance learning and teaching. So far, little attention has been paid to research students' understanding of the feedback process, or how they use feedback to improve learning or to modify the teaching they experienced. As Robinson (2015) has argued, "at a basic level, the accent in education should focus on creating conditions in which students will desire to learn and will be able to learn" (p. 119). If teachers' essential role is to facilitate the learning process, then the value of student's feedback must be considered a key-factor to improve teaching and learning $[2,4]$. But without the learner's perspective, the most important affective and interactional aspects of learners' responses to feedback are missing.

Feedback is considered by Pânișoară (2017) "one of the best motivators of the teacherstudent relationship" (p.107). The feedback provided by teachers and the one provided by learners share the same importance in the didactical process. It's important for teachers to focus on the positive feedback, that is correctly understood by students. Negative feedback can have a strong impact on student's motivation and self-esteem. Whenever possible, Clark argues (2004), "it is highly successful when we are able to show students exactly how much they have learned and have grown over a school year" (p. 101).

Gordon (2011) sustains that the quality of feedback can create the difference and the effectiveness of the educational relationships between teachers and students, where respect is mutually assured. Students are extremely sensitive to teachers' verbal and non-verbal feedback. Their rights, spirit, self-esteem, creativity and natural desire to learn can be educated, encouraged or mutilated. Any message can be a proof that the teachers trust, or they don't trust their students' abilities. If feedback is efficient, students' see that their ideas are respected, understood and accepted [1].

Through feedback, the student is recognized as the most important client of the school. If teachers don't receive enough feedback from their real clients, or they don't ask for it, school will never know how to improve its educational services [5]. Students' voice needs to be known and trusted, and teachers should guide and show them in every way possible that they are cared for, in order to teach them to enjoy life and learning [8]. Hattie (2014) claims that teaching and learning become visible through quality feedback, that provides students higher chances to perform better. If students understand deeply the meaning of what they learn, then the formative values of feedback are clearly assured. The strong bond between challenge and feedback are also highlighted by the author. Best teachers reflect and develop their teaching strategies based on the feedback offered by students [6]. In such an environment, where a teacher is attentive constantly to the type and the quality of impact he has on each learner, students can learn and explore knowledge feeling safe and supported [7]. 


\section{Purpose of the study}

In this paper we attend to asses what students from "Lucian Blaga" University of Sibiu, România, that are following the training for a teaching career, consider to be the value of their feedback during courses and seminars, in order to reflect on the fulfillment of their specific learning needs and on teachers' real interest to support them and consider their voice as a factor of improvement. The key argument of this study is that feedback constitutes a central aspect of learning and the most powerful influencer of student's achievement, yet has been largely neglected in research to date, particularly from the student's point of view. This gap in practice has been picked up by the Department for Teacher Training of our university. The aim of this investigation is to explore first year students' perception of feedback, in order to clarify their real and urgent needs of support for a better learning. We are searching for new ways of developing teachers-students educational partnership, with specific measures to create a professional and healthy environment for our students.

\section{Methodology}

First year 20 students enrolled at the Primary and Preschool Pedagogy program were invited to attend focus groups and individual interviews. They were voluntarily involved in the first part of the study, considering the relevance of the theme for students' academic success. They had the chance to analyze to current situation of the teacher-student relationships and to reflect on how teachers value their feedback. A questionnaire was developed from themes identified in the focus groups and was administrated to a large group of 85 undergraduate students that are following the Psyche-pedagogical Module, inside the Department for Teacher Training, in the second part of the study. This paper reports on the focus groups and the themes that emerged from the data. The survey was built to reveal their learning needs and their vision about student's feedback in the academic education:

- Is feedback what you expected it to be? Why or why not?

- How important is feedback for your learning?

- What kind of feedback do you prefer?

- Do you feel you receive and give enough feedback?

- Are teachers encouraging student participation and ownership of the feedback process?

- How do you think feedback can be improved?

We examined the personal arguments and the evidence presented by students, having the support and expertise for analyzing the findings of the teachers from our department, that are tutors of first year students.

\section{Findings}

Evidence shows that the quality of feedback has a huge impact on students learning and motivation. An important reason to provide feedback to teachers was to call for teachers' awareness of the effectiveness of their pedagogy in relation to meeting learning needs. As students could learn from feedback, so too, could teachers. Ethics approval was sought and given by the University Ethics Committee and the interpretations of students' views were challenged, reviewed and redefined with students' consent.

The first group of 20 students from the Primary and Preschool Pedagogy program were invited to take part based on their options to become voluntarily co-researchers. This program 
type was target as it was expected the students had experience of giving feedback, during their first year of training to become early childhood educators for preschool and primary school, which was crucial for the study. They started focus-group meetings with a deep analysis of feedback's role and significance during university training for the teaching profession, in a modern world. The interviewer asked a series open ended questions, about the kind of feedback they prefer, like verbal, generic/specific, group/individual and about the relevance of teachers' feedback for their learning motivation and process. Focus groups were recorded with written conclusions and the students involved had a wide range of backgrounds in terms of experience background, so we believe that the opinions expressed reflect the range of voices of the students' population from the first year of study. The data collected from all the respondents were used as relevant information about the students' needs to be trusted and valued as educational partners. A qualitative approach was used to collect the data that provided all details, like thought processes, feelings and emotions. Deep reflections were processed in order to generate the basic themes of the questionnaire that was the main result of the focus groups work. The study attempted to glean inside into the worlds of first year students for whom it was anticipated that different experiences of giving feedback might occur.

The second part of the study involved the administer of a closed-form questionnaire developed from the themes identified in these interviews and focus-groups. A group of 85 undergraduate students that are studying at the Psyche-pedagogical Module inside the Department for Teacher Training were voluntarily involved, based on their interest for the topic researched. Students' perspectives related to the usefulness of feedback they offer and receive from teachers for their learning, painted a complex and contradictory picture. Findings underscore that students' reactions and responses to feedback were emotional, variable and context dependent.

At the first question - Is feedback what you expected it to be? Why or why not? the data registered allowed us to gain insights into students' understandings and practice of feedback. Responses to this question revealed differences in students' perceptions of its role and purpose. Qualitative analyses were made in order to explain to major perceptions: some students considered feedback as a giving information about teachers' expectations and a clear justification of the marks they get, others considered the role of feedback as a guidance that lets them know how well they learned. Feedback's most important function according to many students, was in its ability to assist in preparation for the exams, and for applying skills from one area of study to another. Students emphasized its role as a strong motivator for a better learning or self-esteem. They can get higher marks when they receive a clear feedback about their strengths and weaknesses.

Second question developed was: How important is feedback for your learning? All students responded that feedback is important to them and it is useful for their learning' improvement and assessments. They recognized the power of feedback to support learning and teaching. The reasons students wanted to give feedback to their teachers were contradictory. First, students realized that if teachers were to support them with their learning then they had the responsibility to disclose misunderstandings, misconceptions or areas of confusions. Providing signals to teachers that learning was not progressing as expected was a reference point for a continuing dialogue between teacher and student. Students hoped that such dialogue would result in the establishment of individual learning goals that could meet their needs.

Next question, What kind of feedback do you prefer? allowed students to spoke of their own perspectives and needs of feedback from teachers. They also recognized that it's hard for teachers to understand everyone's needs, because everyone is different. On the other hand, their learning needs are changing constantly, they are not static. Teachers who accepted unsolicited feedback from students were perceived as having dispositions receptive to it. 
Such teachers created classroom environments in which the giving of informal feedback and meeting of individual needs seemed to evolve as a result of the quality in their interactions. These types of teachers create a positive and comfortable, environment, based on easy and respectful learning relationships that are helping students to feel positive about giving feedback.

Unfortunately, they argue that just a small part of teachers held contemporary understandings related to students' voice and needs. While students felt it is important to provide feedback to their teachers in relation to the effectiveness of their pedagogy, they were also sensitive to their teachers' feelings and the potential risks to the teacher-student relationship. Recognizing that feedback evokes an emotional response from the recipients of feedback, students were at times faced with the dilemma of hurting their teachers' feelings and thus questioned whether they could tell the complete truth. In environments where teacher reactions were not perceived as positive, students were aware of the inherent risks to themselves in asking questions of their teacher. In another instance, experience of a teacher's negative reaction to the asking of questions discouraged further help-seeking and invoked feelings of helplessness in students. Findings reveled that issues of trust in the relationship between teacher and students seemed to affect the willingness of some students to give feedback.

Responses were mixed to the next question of whether enough feedback was being provided - Do you feel you receive and give enough feedback? Were feedback was provided, it was generally reported as being relevant and related to the students' learning needs. They commented that some lectures were generally willing to provide additional feedback by request, or via email or during consultation hours. Several students claimed that many teachers offered them a feedback too rare or too late, after the semester had ended, attributing this to the large class sizes in their learning early undergraduate years, and to the teachers not having enough time. They interpreted that those teachers' kind of feedback proves a lack of confidence in their abilities as learners. Findings revealed that receiving late and minimal feedback during the semester was a common cause of students' dissatisfaction. They indicated they wanted a more proactive approach from the academic staff, because they recognized the value of feedback as central to improved learning.

The question - Are teachers encouraging student participation and ownership of the feedback process? challenged students to indicate if their voice is really heard. Many claimed that most teachers address general issues or problems about a certain assessment item, without encouraging students to express their own perspectives. If some students are not interested to seek clarification, many are disappointed if they are not directly involved in the feedback process. Informal feedback given spontaneously when students realized they required individual assistance from their teachers was regarded as being of optimal benefit to their learning. If teachers were interested about providing opportunities where thoughtful and insightful feedback could be given to each student particularly, then the last five minutes of each end of lesson could not be enough. Formal written feedback opportunities which enabled students to maintain a level of autonomy and avoid the possible humiliation of disclosing misunderstandings and misconceptions in front of their peers were valued by many respondents.

The last question was the most challenging one, for all students involved: How do you think feedback can be improved? They provided a variety of suggestions to improve feedback from their teachers. Most of them were convinced that teachers should give them feedback not only for assignments or exams, but also to all aspects of a course, to help their motivation for learning. Some teachers gave just the marks, not even helping them to focus on their lower results, in order to understand how to improve their results. Students felt that providing late feedback was particularly disrespectful. $80 \%$ of the students involved expressed a need for additional feedback to help them prepare for all the assessments. They also wanted their 
teachers to care more about student's voice, about what they teach and what students' think and feel. Feedback needs to be perceived as timely and relevant to the students' future studies, focused and valued, aware of students' perceptions, and sensitive.

In line with the findings, the answers of the second group proved that $95 \%$ of students recognized the value of feedback as central to improve learning. Feedback is unhelpful when it is vague, untimely, and when enough information isn't provided to make it useful. The answers of the second group were distributed to their colleagues, 182 students that are studying the Psyche-pedagogical Module, and to all 23 teachers from the Department for Teacher Training as a written report with the main findings. The impact of the study is relevant both for students and teachers involved, in order to improve their communication and mutual feedback. Students need more engaged teachers, because even if some of them are trying to provide helpful feedback, this practice is inconsistent across the faculty, because of time constraints and large class size. But our students, particularly in our department, will become future teachers, feedback is a big cause for concern. They should be more involved to take greater responsibility for their learning and teachers should be more open to students' questions. Providing feedback with no marks can help them get an idea of how they are progressing and required assessments can be self-assessed, in order to help students to improve their learning. The diversity of preferences in order to improve feedback suggests that a balance approach would be most useful. Some prefer verbal or written feedback, and many students would like more opportunities for individual feedback from their teachers. The study needs to be extended to a larger number of students and teachers inside our university, in order to improve the role of student's feedback.

\section{Conclusions}

The present study illustrated students' views about the role of feedback. It also gave them the opportunity to reflect on its importance in their learning. From their responses the academic staff can make improvements to the way feedback is communicated to students and to practical considerations such as timeliness and type of feedback. It also demonstrates that the quality of student experience can be improved: even if teachers are convinced that they give enough and appropriate feedback, the students have different perceptions. Students involved appreciated the opportunity given to say what they thought and to have their voices heard. The provision of feedback to teachers was considered beneficial in two respects: firstly, to have their own learning needs addressed in class, and secondly to motivate their teachers to adapt their practice to suit the learning needs of their students.

Students in the current study considered they needed to work alongside their teachers to generate feedback about their needs. Being able to give spontaneous feedback and to engage in a dialogue with teachers at a time a learning issue arose is beneficial. They hoped that teachers could adapt their pedagogy by seeking and acting on the feedback provided by their students as information that shaped teaching, in order to improve students' competences. Future studies can be developed to find better solutions, in order to explore ways to improve the quality and effectiveness of feedback and to highlight the importance of developing a much deeper dialogue with students about their needs. Further examinations of how students receive and respond to feedback, would be an interesting approach of research to explore.

\section{References}

1. A. Cury, Copii străluciți, elevi fascinanți. Importanța gândirii, a creativității și a visurilor, Editura For You (2018)

2. P. Jones, Rethinking childhood. Attitudes in contemporary society, Continuum (2009) 
3. I.-O. Pânișoară, Profesorul de success: 59 de principii de pedagogie practică, Polirom, (2009)

4. I.-O., Pânișoară, Ghidul profesorului, Polirom (2017)

5. T. Gordon, N. Burch, Profesorul eficient: programul Gordon pentru îmbunătățirea relației cu elevii, Editura Trei (2011)

6. R. Clark, The excellent 11: qualities teachers and parents use to motivate, inspire, and educate children, Hyperion (2004)

7. J. Hattie, Invățarea vizibilă: ghid pentru profesori, Editura Trei (2014)

8. R. Clark, The essential 55: discover the successful student in every child, Piatkus (2010)

9. Robinson, K., Școli creative: revoluția de la baza învățământului, Publica (2015) 